J. Lake Sci. (湖泊科学), 2012, 24(6): 883-890

http: //www. jlakes.org. E-mail : jlakes@niglas.ac.cn

(c) 2012 by Journal of Lake Sciences

\title{
环境规制对无锡市区污染密集型制造业区位选择的影响”
}

\author{
高 爽 ${ }^{1,2}$,魏也华 ${ }^{3}$, 陈 雯 ${ }^{1}$ \\ ( 1 : 中国科学院南京地理与湖泊研究所,南京 210008) \\ (2: 中国科学院研究生院,北京 100049) \\ (3: 犹他大学地理系及公共与国际事务研究院,盐湖城 84112-9155)
}

\begin{abstract}
摘 要: 随着生态环境的恶化, 发达地区制造业区位选择表现出强烈的环境容量制约性和政府规制主导性. 本文在对 1998-2008 年无锡市区污染密集型制造业格局演变分析的基础上,构筑了引人环境规制影响因子的企业区位演变理论 分析框架, 并运用 GIS 空间自回归模型, 对以上理论框架进行验证. 结果表明,1998-2003 年影响企业区位选择的主要要 素为交通可达性、土地价格、开发区规划等,而环境规制相关要素对其影响不显著;而 2003-2008 年,表征环境规制影响 强度的水质目标、清水通道等因子对制造业区位选择的影响显著,这表明环境规制开始成为影响污染密集型制造业区位 的重要因子.本研究对于正确制定城市产业结构调整政策和合理引导经济环境协调发展具有重要的理论借鉴意义.
\end{abstract}

关键词: 环境规制; 区位选择;污染密集型制造业;无锡市区

\section{Effects of environmental regulation on location choice of pollution-intensified manufactur- ing enterprises in Wuxi City}

\author{
GAO Shuang ${ }^{1,2}$, WEI Yehua Dennis ${ }^{3}$ \& CHEN Wen ${ }^{1}$ \\ (1: Nanjing Institute of Geography and Limnology, Chinese Academy of Sciences, Nanjing 210008, P. R. China) \\ (2: Graduate University of Chinese Academy of Sciences, Beijing 100049, P. R. China) \\ (3: Development of Geography and IPIA, University of Utah, Salt Lake City, Utah 84112-9155, USA)
}

\begin{abstract}
With the deterioration of ecological environment, the location choices of manufacturing industries are becoming more restricted by environmental capacity and government regulation. This paper highlights the impact of environmental regulation on the location choices of manufacturing industries. Wuxi City is selected as a case since it has faced most intensive conflicts between economic development and environmental protection. Based on the neo-classical location choice theory of manufacturing industries and the existing literature on the evolution mechanism of industrial locations, this paper established a new analytic framework of combining both traditional factors and environmental regulation factors so as to explain the location choices of pollution-intensified enterprises in Wuxi City from 1998 to 2008. We further applied a GIS-based spatial autoregressive model to explore the effects of environmental regulation on the distribution of manufacturing industries in Wuxi City. Results showed that during 1998 and 2003 the location choices of pollution intensified enterprises were mainly affected by the traditional factors such as transportation accessibility, land prices and the development zone planning, while the influence of environmental regulation factors was not significant. However, from 2003 to 2008 , the environmental regulation emphasizing water quality and channels of clean water supply showed a strong effect on the location choices of pollution enterprises. This result suggested that environmental regulation has become an important factor affecting the locations of pollution intensified manufacturing. This study provides an important reference not only for the policies of industrial structure adjustment but also for the theories about the coordinated development of urban economy and environment.
\end{abstract}

Keywords: Environmental regulation; location choice; pollution-intensified manufacturing enterprises; Wuxi City

* 教育部人文社会科学重点研究基地重大项目 (11JJDZH005)、国家自然科学基金项目 (41130750) 和中国科学院知 识创新工程重要方向项目 (KZCX2-YW-339) 联合资助. 2011-12-31 收稿;2012-03-08 收修改稿. 高爽,女,1984 年生,博士;E-mail: gaoshuangwjc@163.com. 
我国东部发达地区制造业集聚发展, 已经成为区域经济增长的主要动力, 但是以大规模生产和消耗资 源为主的传统工业增长模式所带来的环境问题日益凸显, 有限的环境容量对经济的制约已经相当严重 ${ }^{[1]}$. 在此背景下,地方政府开始通过采取相应的环境政策和法规,在空间上对污染企业的准人加以规划和控制, 产业分布开始向郊区和环境准人门槛低的区域发展, 因而制造业区位选择表现出地方政府环境规制的强烈 主导 ${ }^{[2]}$.

环境规制对产业布局的影响一直是环境与贸易领域争论的焦点问题, 主要集中在对 “污染天堂假说” 的 理论和实证研究 ${ }^{[3]}$. “污染天堂假说” 是指在产品贸易壁垒减少的前提下, 污染型行业必然会选择从环境规 制强度大的地区转移到环境规制强度小的地区 ${ }^{[4]}$. 虽然该假说在理论上较为合理, 但是众多学者通过实证 得出环境规制强度变化对大多数的制造业布局影响并不显著 ${ }^{[5-7]}$. 主要原因是:一是将环境规制强度当成是 影响产业转移的唯一或最重要的因素, 但实际上企业在进行区位选择时, 不仅会考虑到环境规制的影响, 还 需要考虑其他诸如劳动力成本、市场等多种因素的影响 ${ }^{[8-9]}$. Verbeke 等引人新经济地理学 ( New Economic Geography, NEG) 分析框架来评估环境规制对产业布局的影响, 发现环境规制对产业布局的影响比较小, 产 业布局除了考虑环境规制引起的成本大小外, 还会考虑集聚经济以及收人效应 ${ }^{[10]}$. 二是在研究尺度上, 大多 数的研究多集中于区域或更大尺度层面污染企业跨境转移的实证 ${ }^{[11-12]}$, 而 Jeppesen 等通过研究表明, 越小 的地理尺度范围内, 环境规制对制造业区位影响的作用越明显, 这是由于小尺度条件下其他影响制造业的 各种因素都较为一致, 而在较大区域范围内变量的空间异质性对分析结果影响较大 ${ }^{[13]}$, 但是, 目前在市域尺 度上,地方政府环境规制对制造业空间转移的影响,还缺少足够的研究.

本文以无锡市区为例, 从制造业企业区位选择的角度, 探讨城市内部环境规制对制造业空间布局的影 响, 不仅可以从理论上丰富环境规制对产业布局影响的研究, 而且对于科学引导城市污染密集型产业布局 具有重要的借鉴意义.

\section{1 理论框架}

新经济地理学认为,决定经济行为和经济要素在空间上是收玫还是扩散取决于两种力量: 向心力和离 心力. 交通、劳动力、技术水平等向心力使得制造业在空间上集聚, 而由于过度集聚所产生的“市场拥堵效 应”、“资源瓶颈压力” 等离心力使得制造业趋于分散, 制造业总体格局在以上离心力和向心力作用下处于动 态平衡状态 ${ }^{[14-15]}$. 然而, 在中国, 各类空间资源是地方政府通过行政权力可以直接干预的, 城市产业布局的 演变,很大程度上是制度变迁诱致的结果 ${ }^{[16]}$.

我国大城市的城市空间和产业布局调整主要是通过规划布局调整实现的, 随着城市土地有偿使用制度 的建立, 政府主要通过 “退二进三” 的土地空间置换对内城空间和产业布局进行调整和改造, 制造业企业开 始由中心城区逐渐转移到近郊区或者远郊区, 然而由于地方政府在产业布局上往往追求大而全, 制造业空 间不断曼延, 以经济利益为主的 “推大饼” 扩张式的发展已经超出了环境的承载力, 导致城市水环境的极度 恶化 ${ }^{[17]}$. 在此背景下, 以无锡为首的发达城市, 开始以区域环境容量的地区分异为原则, 以政府对制造业企 业的相关环境规制为主导, 进行新一轮的以“环境保护和创新”为主的制造业空间发展转型 (图 1). 因此, 城 市发展依次经历了均衡发展、非均衡协调发展和统筹协调发展的阶段.

\section{2 研究方法}

根据以上的理论分析, 影响无锡市制造业的主要因素为环境规制、土地使用制度、开发区规划以及交通 因素. 因此, 本文以小流域为分析单元, 在确定影响制造业空间布局各要素的基础上, 运用空间自回归模型, 考察环境规制以及各要素对制造业分布的影响机制.

\section{1 分析单元的确定}

本文根据主要河流的自然综合特征, 将区域划分为若干个环境单元, 以此作为评价单位来分析 ${ }^{[18]}$, 主要 原因有二:一是本文的数据涉及多个年份, 地区的行政区划在此期间有一定的调整, 可以避免以行政区划中 街道和建制镇为分析单元所产生的数据不统一问题; 二是本文主要考察环境规制对制造业区位选择的影 响, 涉及环境规制的空间变量较多, 因此以河流的自然综合特征为划分依据更具有针对性. 根据无锡市区的 


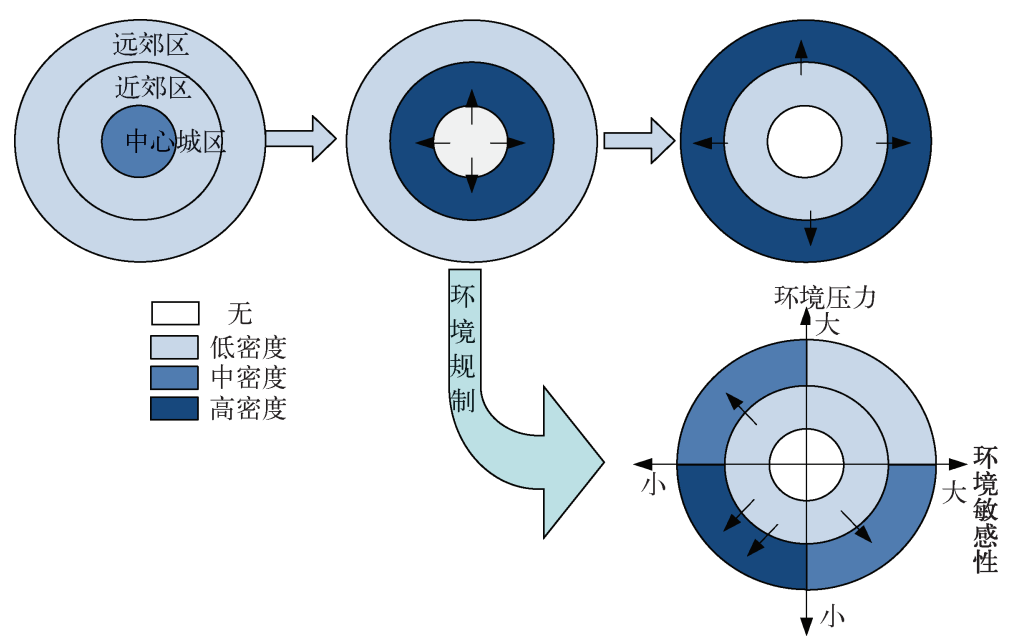

图 1 制造业区位变化示意图

Fig. 1 Schematic diagram on location choice of manufacturing industry

水系格局以及总面积,将其划分为 6 个流域单元 (图 2 ). 在此基础上,以骨干河道为经络,按照所含河流的 主导流向、分水区位置、干支流交汇特点、上中下游不 同河段及两侧陆域汇水等,进一步划分为 47 个二级 环境评价单元.

\section{2 计量模型}

空间经济计量学是一门新兴的边缘科学,近十几 年空间计量模型在国外社会科学很多领域的运用日 益广泛 ${ }^{[19-20]}$. 本文所涉及的制造业区位选择, 很可能 在空间上存在交互影响,必须充分考虑到空间依赖性 和异质性等特点.

在建模过程中,空间依赖性的表现形式分为两 类:一是以空间滞后的因变量或自变量的形式出现在 模型中,即空间滞后模型; 二是以空间自回归的形式 出现在误差项中, 即空间误差模型.

当自变量或因变量之间出现空间依赖性或空间自相关时,可以将模型设定为:

$$
y=x \beta+\rho W X+\varepsilon
$$

本文在此基础上,建立各要素与企业空间分布的多元回归模型:

$$
\begin{gathered}
y=X_{1} \beta_{1}+\rho_{1} W X_{1}+\mu_{1}+X_{2} \beta_{1}+\rho_{2} W X_{2}+\mu_{2}+\cdots \cdots+X_{K} \beta_{1}+\rho_{K} W X_{K}+\mu_{K} \\
\mu_{K}=\lambda W_{\mu K}+\varepsilon_{K}
\end{gathered}
$$

式中, $y$ 是因变量 (评价单元企业个数) 的观测值向量 $(N * 1) ; X$ 是自变量 (各要素) 的观测值矩阵 $(N * K)$; $W$ 是预先设定的空间权重矩阵 $(N * K)$, 空间权重以每个分析单元是否相邻赋值; $W X$ 是自变量的空间滞后; $\varepsilon$ 是 $N * 1$ 的误差项向量, $\rho$ 是空间自回归系数, $\beta$ 是 $K * 1$ 的回归系数向量. $\lambda$ 是误差项的空间自回归系数; $W_{\mu K}$ 是误差项的空间滞后; $\varepsilon_{K}$ 是不相关的、同方差的误差项.

当 $\rho=\lambda=0$ 时, 为普通回归模型, 它意味着模型中无空间特性的影响; 当 $\rho \neq 0, \beta=\lambda=0$ 时, 为一阶空间 自回归模型. 该模型类似时间序列分析中的一阶自回归模型, 反映变量在空间上的相关特征, 即所研究区域 
的企业区位选择是否受到相邻区域企业聚集程度的影响; 当 $\rho \neq 0, \beta \neq 0, \lambda=0$ 时, 为混合回归与空间自回 归模型, 即空间滞后模型, 表明所研究区域的企业个数不仅与本区域的各要素有关, 还与相邻区域的企业 集聚度有关; 当 $\rho=0, \beta \neq 0, \lambda \neq 0$ 时, 为残差空间自回归模型, 即空间误差模型, 表明所研究区域的企业密 度 $(y)$ 不仅与本区域的要素 $(X)$ 有关, 还与相邻区域的企业密集度 (表现为 $W_{y}$ ) 以及各要素 $($ 表现为 $W X)$ 有关.

空间自回归模型参数的估计不适合采用普通最小二乘估计 (OLS), 因为空间项的存在导致 OLS 不仅有 偏, 而且不一致. 本文采用极大似然估计方法 (MLE) 来估计模型中的参数. 空间自回归模型中基于 MLE 的 渐近检验方法是常用的拉格朗日乘子 ( $L M)$ 以及 Moran's $I$ 检验. 对于一般空间自回归模型, 待估参数 $\theta=$ $\left(\beta^{\prime}, \rho, \lambda, \sigma^{2}\right)$,构造基于 $y$ 的 $\lg$ 似然函数:

$$
L(\theta)=-\frac{n}{2} \lg \pi-\frac{n}{2} \lg \sigma^{2}+\lg |B|+\lg |A|-\frac{1}{2 \sigma^{2}} v^{\prime} v
$$

式中, $A=I-\rho W ; \beta=I-\lambda W_{\mu K} ; v^{\prime} \nu=(A y-X \beta)^{\prime} B^{\prime} B(A y-X \beta)$; 要求 $\rho 、 \lambda$ 满足: $|I-\rho W|>0>\left|I-\rho W_{\mu K}\right|>0$.

\section{3 变量定义}

由于本文主要考察环境规制对制造业区位选择的影响, 所以主要以分析单元的企业个数作为被解释变 量 $y$ 来表征制造业区位空间格局, 以单元的环境规制程度作为解释变量.

表征环境规制强度的指标包括污染源治理费用、废水达标排放量等有关的环保投资等,但是此类指标 只适用于区域层面的分析, 而对于小尺度的环境规制强度如何评价还较为少见. 本文主要选择对制造业区 位选择有较大约束力的水质目标、清水通道以及生态功能区面积占比, 作为小流域单元内环境规制强度的 替代指标 (表 1 ).

1) 水质目标指一定时期内, 为保证水体质量和水域使用目的而制定的目标水质类别, 它能够最直接地 表征政府规制对小流域水环境治理和企业准人所产生的强制性. 按照《地表水环境质量标准》, 水质目标一 般分为 $\mathrm{I} \sim \mathrm{V}$ 类, 类别越低对汇水流域的排污控制越严格, 规制强度越强. 据此, I II 类水质目标流域赋 值为 1 分, III $\sim \mathrm{IV}$ 类为 2 分, $\mathrm{V}$ 类及以上为 3 分.

2) 清水通道是跨流域调水输水的重要通道, 水质要求较高, 水源安全保障的约束较强. 研究区域的清水 通道主要包括望虞河、梁溪河、直湖港等, 根据是否有清水通道过境区域进行赋值, 流域内有清水通道通过 赋值为 1 分, 否则为 0 分.

3) 生态功能区指区域内的生态红线区或禁止开发区. 生态功能保护区内执行严格的环境保护政策,同 时对一定范围以外的区域也有一定的限制,一个地区内这类保护区域面积越大, 代表环境规制的强度越大, 对制造业的准人要求越高. 采用研究单元内重要生态功能保护区面积百分比赋值, 作为制造业准人的主要 因素.

除以上表征环境规制强度的解释变量外, 模型引人以下影响制造业分布的传统变量作为控制要素 (表 1).

1) 开发区工业园区建设. 政府通过 “退城进园” 将市区或者环境敏感地区的污染密集型制造业企业进 行搬迁, 以便对污染进行更好的控制和集中处理, 因此, 具有市级以上开发区和乡镇工业集中区的研究单元 赋值为 1 , 否则赋值为 0 .

2) 土地价格. 土地价格的差异是制造业区位选择的重要因素, 土地由无偿划拨到有偿使用加速了工业 郊区化的进程. 本文根据《2007 年无锡市土地级别及基准地价成果》中的工业土地定级给研究单元赋值, $\mathrm{I} \sim \mathrm{II}$ 级土地赋值为 $1, \mathrm{III} \sim \mathrm{V}$ 级赋值为 $2, \mathrm{~V}$ 级以上赋值为 3 , 同时具有不同登记地价的研究单元取最高等 级值赋值.

3) 交通区位. 重要的交通干线和枢纽设施通过改变交通可达性从一定程度上决定城市的空间发展形 态, 制造业的发展无疑会向着更有优势的区位靠拢. 因此, 有高速公路、铁路以及机场等重要交通枢纽通过 的流域赋值为 1 , 否则赋值为 0 . 
表 1 影响制造业区位选择的要素及赋值标准

Tab. 1 Factors affecting location choice of manufacturing industry and assignment criteria

\begin{tabular}{|c|c|c|c|}
\hline 类型 & 名称 & 编码 & 赋值 \\
\hline 被解释变量 & 企业密集度 & $y$ & 单元内规模以上企业个数 \\
\hline \multirow[t]{3}{*}{ 解释变量环境规制强度 } & 水质目标 & $X_{1}$ & $\mathrm{I} \sim$ II 类、 III $\sim$ IV 类、 $\mathrm{V}$ 类及以上分别赋值为 $1 、 2 、 3$ \\
\hline & 清水通道 & $X_{2}$ & 有清水通道通过赋值为 1 , 否则为 0 \\
\hline & 重要生态功能保护区面积 & $X_{3}$ & 单元内该类型区面积占比 \\
\hline \multirow[t]{3}{*}{ 控制变量 } & 土地价格 & $X_{4}$ & 根据主城区工业用地级别赋值 \\
\hline & 开发区规划 & $X_{5}$ & 有市级以上开发区赋值为 1 , 否则为 0 \\
\hline & 交通可达性 & $X_{6}$ & 有高速公路和机场通过赋值为 1 , 否则为 0 \\
\hline
\end{tabular}

\section{3 研究区域背景: 无锡市区制造业格局演变过程}

随着 1980s 乡镇企业的异军突起, 无锡的工业分布在空间形态上形成了 “村村点火, 户户冒烟” 的分散 格局, 虽然促进了当地经济飞速发展, 但是规模不经济性导致了严重的工业污染问题 ${ }^{[21]} .2005$ 年开始, 无锡 市各级政府为了落实中央政府提出的“科学发展观”, 就开始提出通过关闭“五小”、“三高两低”企业淘汰高 能耗、高污染和低附加值的企业, 启动企业退城进园, 引进技术含量高的新兴制造业企业等优化产业结构布 局. 期间, 太湖水危机事件将无锡市推到了风口浪尖, 促使政府不断出台产业布局调整意见 ${ }^{[22]}$. 可见, 无锡市 的污染密集型制造业格局演变过程主要是政府执政理念和环境危机所引发的环境规制强度转变的体现.

为了分析政府各项规制政策对制造业区位的影响，根据无锡市相关部门提供的规模以上企业的名录， 通过对企业进行空间化, 建立了 1998-2008 年企业点位的空间数据库. 根据相关文献 ${ }^{[23]}$ 分析以及无锡市区 的制造业发展状况, 主要选择纺织业、食品制造业、造纸业、石油化工业、冶金业等企业作为污染密集型的产 业研究对象, 该五类行业污染排放量占到全部行业的 $85 \%$ 以上 ${ }^{1}$. 由于数据库中的企业以空间点位数据为 主, 且考虑到期间行政区划的变动, 本文主要基于点数据的模式计算整个区域的产业集聚情况, 具体采用估

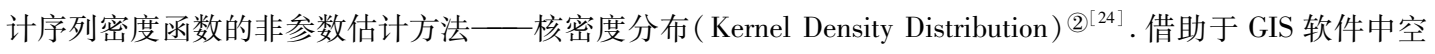
间分析模块的密度分析命令计算每个网格的企业分布密度值,并将网格单元的核密度值进行聚类分析.

随着对于制造业布局的环境规制政策的从无到有, 无锡市区的污染密集型企业由原先的以靠近中心 城区和主要的交通干道为主的集聚格局逐渐向郊区和远离太湖地区扩散和重新集聚格局转变. 此外, 由 于造纸、饮料、纺织等一些高污染低附加值的企业逐渐被 “关、停、并、转”, 并逐渐进人园区, 无锡市区的污 染密集型制造业的结构日趋调整, 核密度值的逐年增加也表明污染企业在空间上表现出集聚度提高的态 势(图 3).

\section{4 结果与分析}

通过对不同年份解释变量与被解释变量、控制变量的空间关联性诊断结果得出, 各个年份的 Moran's I 指数都呈现了显著的自相关, 而其他各类检验指数也出现了不同显著水平的相关性, 此外, 用来检验异方差 的 Breusch-pagan test (经过空间修正) 在样本中都显著, 这都表明评价单元内的企业布局不仅与相关要素有 关, 还与其周围分析单元内企业密集程度有关 (表 2). 同时, 通过对 3 种模型的拟合结果可以看出, 1998 年 和 2003 年空间滞后和空间误差模型的拟合程度都显著高于普通回归模型, 而 2008 年拟合度相当, 因此, 本

(1) 引自《无锡市统计年鉴 2009》.

(2) 核密度分布 (Kernel Density Distribution), 即以每个待计算网格点为中心进行圆形区域的搜索, 进而计算每个网 格点的密度值. 设 $x$ 处的核密度分布函数为 $f(x)=\frac{1}{n h} \sum_{i=1}^{n} k\left(\frac{x-X_{i}}{h}\right)$, 其中, $x$ 为待估计的企业点位置, $X_{i}$ 为落在以 $x$ 为圆 心 $h$ 为半径的圆形范围内的第 $i$ 个企业的位置, $h$ 为带宽. 选取 $1500 \mathrm{~m} \times 1500 \mathrm{~m}$ 的网格作为输出单元; 带宽 $h$ 根据多次调 试选择 $5 \mathrm{~km}$. 
表 2 空间关联性诊断指标

Tab. 2 Diagnostic indicators of spatial association

\begin{tabular}{lcll}
\hline 空间关联性指标 & 1998 年 & 2003 年 & 2008 年 \\
\hline Moran's I ( error) & $2.902^{* *}$ & $2.134^{* *}$ & $2.213^{* *}$ \\
Lagrange Multiplier( lag) & $5.412^{* *}$ & $3.276^{*}$ & $5.512^{*}$ \\
Robust LM( lag) & $0.970^{*}$ & 0.539 & 0.353 \\
Lagrange Multiplier( error) & $5.719^{* *}$ & $2.772^{*}$ & $3.261^{*}$ \\
Robust LM( lag) & $5.031^{* *}$ & $0.358^{*}$ & $4.111^{*}$ \\
Lagrange Multiplier(SARMA) & 5.916 & $3.311^{*}$ & 6.620 \\
Breusch-pagan test & 10.530 & $13.830^{*}$ & $48.370^{* *}$ \\
\hline
\end{tabular}

$*$ 为 $5 \%$ 显著水平, $* *$ 为 $1 \%$ 显著水平.
文同时选用普通回归模型、空间滞后 和空间误差模型进行研究 (表 3 ).

对 47 个分析单元所有解释变量 相关系数的计算表明,1998 年影响企 业区位选择的主要要素为交通可达性 和土地价格; 2003 年开始, 由于各类 开发区的相继建成, 开发区规划的影 响开始显现, 和交通可达性、土地价格 一并成为影响因子, 但此时环境规制 相关要素影响不显著;而到 2008 年, 环境规制的影响逐渐明显, 表现出了 显著的相关性, 该结论与前文提出的 理论分析较为一致.

表 3 空间滞后和误差模型估计结果

Tab. 3 Results of lag and spatial error model

\begin{tabular}{|c|c|c|c|c|c|c|c|c|c|}
\hline \multirow{2}{*}{ 变量 } & \multicolumn{3}{|c|}{1998 年 } & \multicolumn{3}{|c|}{2003 年 } & \multicolumn{3}{|c|}{2008 年 } \\
\hline & 普通 & 滞后 & 误差 & 普通 & 滞后 & 误差 & 普通 & 滞后 & 误差 \\
\hline$W y$ & \multicolumn{3}{|c|}{$0.8396^{* *}$} & \multicolumn{3}{|c|}{$0.5888^{* *}$} & \multicolumn{3}{|c|}{$0.2703^{*}$} \\
\hline 常数项 & 0.2167 & 0.2644 & 0.2624 & 0.1725 & 0.2191 & 0.2016 & 0.1072 & 0.0941 & 0.0381 \\
\hline 水质目标 & 0.0093 & 0.0037 & 0.0138 & 0.0343 & 0.0281 & 0.0372 & $0.0752 * *$ & * $0.0749 *$ & $0.0927 *$ \\
\hline 清水通道 & 0.0031 & -0.0364 & -0.0219 & -0.0055 & -0.0430 & -0.0353 & $0.0379^{*}$ & $0.0412 *$ & $0.0368 *$ \\
\hline 重要生态功能保护区 & -0.0771 & -0.1186 & -0.0240 & -0.0462 & -0.0436 & $-0.0629-$ & $-0.0089-$ & -0.0121 & -0.0157 \\
\hline 土地价格 & $0.0756^{* *}$ & $0.0746 *$ & $0.0655^{*}$ & $0.0677^{*}$ & $0.0684^{* *}$ & $0.0397^{*}$ & $0.0303^{*}$ & $0.0269^{*}$ & 0.0005 \\
\hline 开发区规划 & 0.0489 & -0.0273 & -0.0080 & $0.0907^{*}$ & 0.0274 & $0.0324 *$ & $0.0085^{*}$ & $0.0029^{*}$ & $0.0107 *$ \\
\hline 交通可达性 & $0.0878 * *$ & $0.0467 *$ & $0.0484 *$ & $0.015^{* *}$ & $0.0813 * *$ & $0.1019^{* *}$ & * 0.1271 ** & *0.0979** & 0.0967 ** \\
\hline LAMBDA & & & $0.9161^{* *}$ & & & $0.7385^{* *}$ & & & $0.5350 * *$ \\
\hline$R^{2}$ & 0.2052 & $0.3951^{*}$ & $0.3867^{*}$ & $0.2723^{*}$ & $0.3617^{*}$ & $0.3686^{*}$ & $0.4255^{* *}$ & $* 0.4508^{* *}$ & $0.4399 * *$ \\
\hline
\end{tabular}

$*$ 为 $5 \%$ 显著水平, $* *$ 为 $1 \%$ 显著水平.

环境规制相关的水质目标 $X_{1}$ 、清水通道 $X_{2}$ 对 2008 年制造业区位选择具有显著作用. 其中, 最能表征环 境规制强度的水质目标 $X_{1}$ 对其影响最为显著, 影响系数达到 0.0752 , 即水质目标每提高 1 个等级 (总共 5 个 等级), 该分析单元的污染型制造业企业数要增加 $15 \%$, 这表明, 为了在短期内达到水体功能的改善, 政府一 方面通过关闭或者转移已有的制造业企业减少污染排放, 另一方面通过提高制造业准人门槛, 禁止或者限 制污染型制造业的准人. 清水通道对制造业区位的影响与水质目标有较大的关联性, 清水通道经过的地区 其水质目标必然较其他地方要求高, 但是其作用比较间接, 且与某些排水通道相互交叉, 因此虽然其表现为 与水质目标较为相似的作用, 但是显著性不高. 而无锡市区重要生态功能保护区基本以水生态与绿生态保 护类型为主, 由于重要生态功能保护区的布局以南部沿太湖流域的滨湖区较为集中, 其他地区相对较少, 少 数丘岗地貌单元呈零散分布状态, 生态调控作用受益范围有限, 因此对整个制造业布局的影响并不十分显 著 (图 4). 此外,2008 年的空间滞后和误差模型的环境规制相关系数检验都不十分显著, 表明分析单元内的 企业区位选择主要受到本单元内环境要素的影响.

控制变量中, 交通可达性是制造业区位选择的首要因素, 这与现有学者们的研究结果较为一致 ${ }^{[25]}$, 说明 城市各类制造业企业都有接近高速公路和主要交通干道的趋势, 城市核心区交通条件的拥堵和外围日益成 熟的交通网络都成为制造业扩散与重新集聚的主要原因, 且相邻分析单元的交通情况对周围制造业企业选 择都有较为显著的影响. 随着 1990s 城市土地有偿使用制度的建立, 土地价格对制造业区位开始有显著的影 响, 但从 2003 年开始, 其影响作用有所降低, 这可能是由于其他因素的空间异质性高于土地价格, 也可能是 由于分析单元的划分导致误差所致. 开发区对污染型企业的区位选择影响不十分显著, 可能是污染密集型 

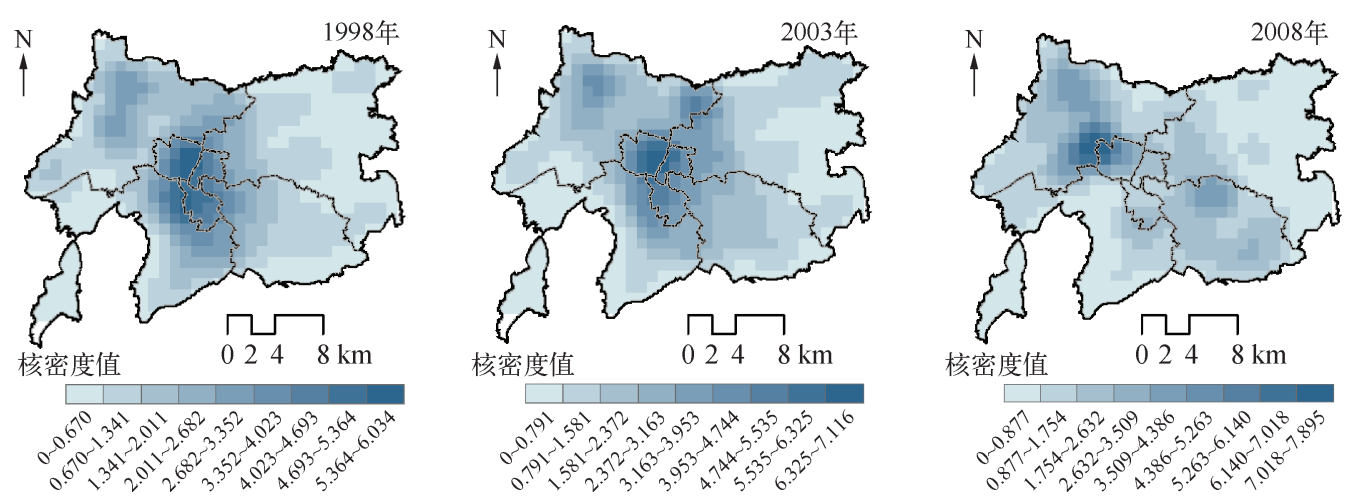

图 3 污染密集型企业分布的年际变化

Fig. 3 Annual changes of distribution of pollution-intensive enterprises

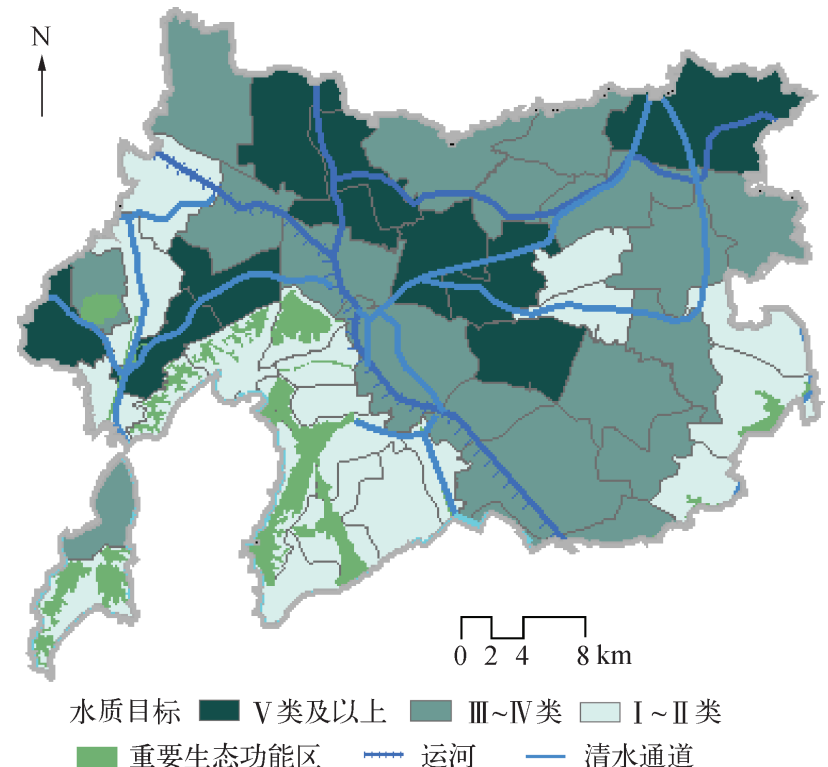

图 4 水环境规制的主要要素分布

Fig. 4 Distribution of the main factors of water environment regulation

企业多集中于较小的乡镇工业集中区,而开发区准人门槛相对较高所导致.

\section{5 结论与讨论}

本文首先全面梳理了无锡市区相关政府环境规制政策以及制造业格局演变过程, 在此基础上,结合现有 对制造业区位选择理论和国内发达地区制造业布局演变的研究, 构筑了加人环境规制影响因子的企业区位演 变机制. 根据以上理论分析, 影响无锡市制造业的主要因素为环境规制强度、土地使用制度、开发区规划以及 交通因素. 因此, 本文以小流域为分析单元, 以制造业企业个数为被解释变量, 以水质目标、清水通道以及生态 功能区面积占比作为表征环境规制强度的解释变量, 同时考虑土地使用制度、开发区规划以及交通因素等影 响,运用空间自回归模型, 对以上理论假设给予验证. 研究发现, 由于城市外围交通改善和土地有偿使用, 1998 年影响企业区位选择的主要要素为交通可达性和土地价格,2003 年开发区规划的影响开始显现, 而到 2008 年, 表征环境规制影响强度的水质目标、清水通道等因子对制造业区位选择的影响显著, 这表明在城市内部, 环境规制已经成为影响污染密集型制造业区位的最主要因子. 作为发达地区典型代表的无锡市区,在水危机 
之后, 相关的环境规制政策显然对制造业布局产生了较为显著的影响, 但是在重要的生态保护区以及水环境 功能区范围内仍有部分污染企业存在, 因此, 除了通过调整产业结构、加强企业的关停并转等遏制环境进一步 恶化的指标政策外,无锡市还要加大对制造业企业排污的市场化监管与治理,提高制造业准人的门槛.

如何协调发达地区城市环境与经济发展的矛盾是可持续发展的主要命题, 而通过相关的政府规制手 段, 克服传统经济中所产生的外部不经济性, 以环境容量为主导调整城市制造业空间布局, 是实现制造业产 业空间结构优化和城市可持续发展的最有效途径. 因此, 本研究不仅可以从理论和实证上丰富城市内部环 境规制对产业布局影响的研究, 而且对于正确制定城市产业结构调整政策和合理引导城市环境和经济的协 调发展具有重要的借鉴意义.

\section{6 参考文献}

[ 1 ] Chertow MR, Ashton WS, Espinosa JC. Industrial symbiosis in Puerto Rico: Environmentally related agglomeration economies. Regional Studies, 2008, 42(10): 1299-1312.

[2] 张京祥,殷 洁,罗小龙. 地方政府企业化主导下的城市空间发展与演化研究. 人文地理,2006,21(4):1-6.

[ 3 ] Ederington J, Levinson A, Minier J. Trade liberalization and pollution havens. Advances in Economic Analysis \& Policy, $2004,4(2)$ : article 6.

[ 4 ] Fullerton D. The economics of pollution havens. Cheltenham: Edward Elgar Publishers, 2006 ( http://works. bepress. com/don_fullerton/26).

[ 5 ] Copeland B, Brian R, Taylor MS. Trade, growth, and the environment. Journal of Economic Literature, 2004,42 : $7-71$.

[6] Jaffe AB, Peterson SR, Stavins RN. Environmental regulation and the competitiveness of United States manufacturingwhat does the evidence tell us? Journal of Economic Literature, 1995, 33 : 132-163.

[ 7 ] Raspiller S, Riedinger N. Do environmental regulations influences influence the location of French firms. Land Economy, 2010, 84(3) : 382-395.

[ 8 ] Taylor S. Unbundling the pollution haven hypothesis. Journal of Economic Analysis \& Policy, 2005, 4(2) : 1-8.

[ 9 ] Mulatu A, Gerlagh R, Rigby D et al. Environmental regulation and industry location in Europe. Environment Resource and Economics, 2010, 45: 459-479.

[10] Verbeke T, Clercq MD. The income-environment relationship: Evidence from a Binary Response Model. Ecological Economics, 2006, 59(4): 419-428.

[11］王芳芳,郝前进. 地方政府吸引 FDI 的环境政策分析. 中国人口・资源与环境,2010,20(6):58-63.

[12] 杨 涛. 环境规制对中国 FDI 影响的实证分析. 世界经济研究,2003,(5):65-68.

[13] Jeppesen T, List JA, Folmer H. Environmental regulation and new plant location decisions: evidence from a meta-analysis. Journal of Regional Science, 2002, $42(1): 19-49$.

[14] Turkey JW. Exploratory data analysis. US: Addition-Wesley Publishing Company, 1977.

[15] Fujita M, Thisse J. Economies of agglomeration. Journal of the Japanese and International Economies, 1996, 10: 339-378.

[16] 张京祥, 吴缚龙, 马润潮. 体制转型与中国城市空间重构——建立一种空间演化的制度分析框架. 城市规划, 2008, (6) :55-60.

[17] 刘盛和. 城市土地利用扩展的空间模式与动力机制. 地理科学进展,2002,21(1):43-50.

[18] 陈 雯, 禚振坤, 赵海霞等. 水环境约束分区与空间开发引导研究——以无锡市为例. 湖泊科学, 2008, 20 (1): $129-134$.

[19] Lesage JP. A spatial econometric examination of China's economic growth. Geographic Information Sciences, 1999, 5: 143-153.

[20] Yu DL. Spatially varying development mechanisms in the Greater Beijing Area: a geographically weighted regression investigation. The Annals of Regional Science, 2006, 40: 173-190.

[21] 藏其胜. 新苏南模式中环境问题的归因分析. 小城镇建设,2006,(12):62-64.

[22] 吴敬琏,黄少卿. 无锡经验一一国经济发展转型的个案研究.上海: 远东出版社, 2010:45-47.

[23] 夏友富. 外商投资中国污染密集产业现状、后果及其对策研究. 管理世界,1999,(3):109-123.

[24] 袁 丰,魏也华,陈 雯等. 苏州市区信息通讯企业空间集聚与新企业选址. 地理学报,2010,(2):1-11.

[25］吕卫国,陈 雯. 制造业企业区位选择与南京城市空间重构. 地理学报,2009,64(2):142-152. 